\title{
Exploring Factors Facilitating Electronic Library Use
}

\author{
Yi-Chii Hsu
}

\begin{abstract}
To understand the factors influencing electronic library use, this study developed a conceptual model according to previous research. The research model hypothesized that personal innovativeness in IT, perceived usefulness of IT and perceived ease of use of IT positively affect attitude toward electronic library, which in turn facilitate electronic library intention and electronic library use. By collecting data from 306 surveys from Taiwan's users, we applied structural equations modeling to test the relationships in the model. Research findings demonstrated that the positive effect of personal innovativeness in IT, perceived usefulness of IT and perceived ease of use of IT on attitude toward electronic library. In addition, attitude toward electronic library has a positive effect on electronic library intention and electronic library use.
\end{abstract}

Index Terms - Personal innovativeness in IT, perceived usefulness of IT, perceived ease of use of IT, attitude toward electronic library, electronic library intention, electronic library use.

\section{INTRODUCTION}

Electronic library, is a library where all or a big part of its everyday operations is carried out with the use of computers (Akpojotor, 2017). Such operations are usually the cataloguing, the search and identification of relative documents, the circulation (lending) of library material, the registration of users, the management of the document orders, the acquisition of new material, the serials and collection management, the usage statistics etc (Edem and Egbe, 2018). The term electronic library refers to the way of management of the documents and operations, the content can of course be printed. In recent times, electronic library has been identified as the major source for information dissemination in the universities, especially for researchers (Quadri et al., 2018). Electronic library acquires, processes, stores, evaluates and disseminates information via electronic means to the audience in need of information. It can serve as a medium for achieving national and community development through provision of relevant information necessary for decision making and policy enhancement (Toyo, 2017). Electronic library is a multi-disciplinary concept that shares various branches of computer science including data management, information retrieval, library science, document management, information systems, the web, image processing, and artificial intelligence (Akpojotor, 2017). The mission of e-library is to provide both information services and resources that are capable of meeting the research, teaching and learning needs of the faculty and students (Toyo, 2017).

Yi-Chii Hsu, Graduate Institute of Library and Information Science, National Taiwan University, Taiwan
Electronic library is popular for many reasons, including: digital journals can be linked from and to indexing and abstracting databases; access can be from the user's home, office, or dormitory whether or not the physical library is open; the library can get usage statistics that are not available for print collections; and digital collections save space and are relatively easy to maintain (Toyo, 2017). The advent of electronic library has not only influenced the way students and scholars conduct research, it has also changed their perception and use of the library and its resources. Electronic library has become popular and "must use" among academic staff and research scholars due to their ability to report research findings more timely and allow remote access without geographical limitations (Akpojotor, 2017).

Despite the important trend of electronic library, to the author's best knowledge, few studies explored electronic library behavior. To understand electronic library behavior, based on previous study, this study proposed that electronic library perception is closely related to electronic library attitudes (Schiffman \& Kanuk, 2000). According to Weeger and Gewald (2014) and Davis (1989), this study proposed electronic library perception comprise personal innovativeness in IT, perceived usefulness of IT and perceived ease of use of IT are crucial factors, and these factors are supposed to influence attitude toward electronic library. The reasons why this study proposed electronic library perception include personal innovativeness in IT, perceived usefulness of IT and perceived ease of use of IT are as follows. First, technology acceptance factors have been included in many models on electronic library intention and have found to be important predictors (Hopkins et al., 2013). Secondly, previous studies suggest that the TAM factors are influenced by personal innovativeness (Lewis et al., 2003).

Moreover, Attitude towards a behavior refers to "the degree to which a person has favorable or unfavorable evaluation of the behavior of the question" (Grandom and Mykytyn, 2004). Attitude can be viewed as the bridge between persons' background characteristics and the behavior that fulfills their needs (Armstrong and Kotler, 2000; Shwu-Ing, 2003). A person's behavior are influenced by attitude (Haque et al., 2006). Hence, this study thus expects that the association between attitude toward electronic library and electronic library intention and electronic library use.

The aim of this study is to explore factors influencing electronic library use, this study developed a conceptual model based on previous studies. This study proposed that personal innovativeness in IT, perceived usefulness of IT and perceived ease of use of IT positively affect attitude toward 


\section{Exploring Factors Facilitating Electronic Library Use}

electronic library, which in turn facilitate electronic library intention and electronic library use. Two hypotheses are proposed and examined with data collected from those who having experience of using electronic library in Taiwan. This study enriches the current literature in several ways. First of all, this study views attitude toward electronic library as a latent mechanism that links electronic library perception (i.e. personal innovativeness in IT, perceived usefulness of IT, perceived ease of use of IT) and electronic library behavior (i.e. electronic library intention and electronic library use). This study proved that electronic library perception is closely related to electronic library attitudes (Schiffman \& Kanuk, 2000). In addition, attitude is directly affected by users' belief about a system, such as perceived usefulness and ease of use (Davis, 1989). Secondly, this study examines the proposed model based on empirical data of customers in a Taiwanese context.

\section{LITERATURE REVIEW AND HYPOTHESES}

electronic library perception and attitude toward electronic library

According to Weeger and Gewald (2014) and Davis (1989), this study proposed electronic library perception comprise personal innovativeness in IT, perceived usefulness of IT and perceived ease of use of IT, and personal innovativeness in IT, perceived usefulness of IT and perceived ease of use of IT has a positive effect on attitude. Specifically, personal innovativeness in IT means that those who are innovative tend to be more risk-averse (Agarwal and Prasad, 1998). Moreover, based on the technology acceptance model (TAM) the main antecedents of the attitude to use a particular technology are perceived usefulness and perceived ease of use (Davis, 1989. Perceived usefulness refers to "the degree to which a person believes that using a particular system would enhance his or her job performance" (Davis, 1989, p.320). While perceived ease of use is defined as "the degree to which a person believes that using a particular system would be free of effort". Thus, it is hypothesized that:

Hla. Personal innovativeness in IT is positively related to attitude toward electronic library.

$H 1 b$. Perceived usefulness of IT is positively related to attitude toward electronic library.

HIc. Perceived ease of use of IT is positively related to attitude toward electronic library.

Attitude toward electronic library and electronic library behavior

Owing to the increasing importance of electronic library, understanding electronic library behavior is beneficial to business management. This study explored electronic library behavior in term of electronic library intention and electronic library use. electronic library intention means the extent person's intention to use electronic library ,whereas electronic library use is defined as the use situation of electronic library BYOD (DeLone and McLean, 1992).

Attitude serves as a strong influence on behavior, attitude research offers a potentially useful device for explaining and predicting person's behavior" (Udell, 1965). Attitudes have been perceived as powerful determinants of behaviors and researchers consider that an individual having a positive attitude toward something is more likely to have some behavior toward the objective (Vantomme et al., 2005). This study proposed that when people have positive attitude toward electronic library, it may generate positive electronic library behavior (i.e. electronic library intention and electronic library use). Thus, it is hypothesized that:

H2a. Attitude toward electronic library is positively related to electronic library intention.

$H 2 b$. Attitude toward electronic library is positively related to electronic library use.

\section{Methodology}

This study applied a survey research method to examine the factors influencing electronic library use. A self-administered survey was sent to Taiwanese consumers.

\subsection{Sample}

The sample was drawn from those who having experience of using electronic library in Taiwan. This study used a questionnaire survey method to collect data. Variables in the questionnaire comprise background information, personal innovativeness in IT, perceived usefulness of electronic library, perceived ease of use of electronic library, attitude toward electronic library, electronic library intention and electronic library use. This study used random sampling and 400 questionnaires were mailed to selected respondents, of the 313 returned questionnaires, 7 are incomplete and the remaining 306 are usable for analysis, representing a response rate of $76.5 \%$.

As to the gender frequencies, there were $58 \%$ female respondents and $42 \%$ male respondents. Second, in the age frequencies, the largest group ranged from the age of 26 years old to 35 years old $(40.2 \%)$ and 36 years old to 50 years old $(21.4 \%)$. In the education section, most respondents are bachelor $(69.2 \%)$.

\section{Measures}

All the items were derived from previous studies and this study used a six-point Likert-type scale to measure the variables. We also provided internal consistency reliability as follows:

Personal innovativeness in IT. To measure this variable, we selected the four items with the highest factor loadings in the original scale developed by Agarwal and Prasad (1998). The sample items such as "Among my peers, I am usually the first to try out new information technologies". The alpha coefficient for this scale was 0.93 .

Perceived usefulness of IT. This variable was measured by a five-item scale. This study used the three items with the highest factor loadings from the original scale developed by 
Davis (1989). The sample items such as "If I used electronic library for work, I would find it easy to get these devices to do what I want them to do". The alpha coefficient for the abbreviated scale was recorded at 0.92 .

Perceived ease of use of IT. Perceived ease of use of IT was measured using a scale that comprised six items with the highest factor loadings in the original scale developed from previous studies (Davis, 1989). The sample items such as "If I used electronic library for financial advice, it would enable me to accomplish tasks more quickly.". The alpha coefficient for this scale was 0.94 .

Attitude toward electronic library. Attitude refers to a person's overall evaluation of electronic library as a tool, which can be positive / favorable or negative / unfavorable. The items used to measure the attitude toward electronic library were modified from the scale developed by Taylor and Todd (1995). Sample item such as "Using the electronic library is a wise idea". The alpha coefficient of this variable was 0.91 with sufficient reliability (Nunnally and Bernstein, 1994).

electronic library intention. To measure this variable, this study selected the three items with the highest factor loadings in the original scale developed by Brown and Venkatesh (2005). The sample items such as "I intend to use the electronic library service". The alpha reliability for this variable was 0.87 . electronic library use. Electronic library use was measured using a scale that comprised three items with the highest factor loadings in the original scale developed from previous studies (Davis, 1989). The sample items such as "I quietly rely on electronic library.". The alpha coefficient for this scale was 0.93 .

\section{RESULT}

Reliability and validity

To test construct reliability, this study used Cronbach's alpha coefficient to examine internal consistency, the overall reliability for all scales exceeds the acceptable level of 0.7 suggested by Nunnally (1978), indicating good internal consistency reliability. Moreover, structural equation modeling was used to examine the relationships in the proposed model. Table 1 shows that all constructs in this study represented significant correlations. This study also tested convergent validity, As observed in Table 2, all $\mathrm{T}$-values are higher than 2 , representing good convergent validity. In addition, this study applied two models (one is constrained model and the other is free model) to compare the chi-square statistics, the findings indicated that free models is better than constrained ones, meaning good discriminant validity.

Table 1 Descriptive statistics and correlations among indicator variables

\begin{tabular}{|c|c|c|c|c|c|c|c|}
\hline Variables & $\mathrm{M}$ & SD & 1 & 2 & 3 & 4 & 5 \\
\hline 1 Personal innovativeness in IT & 4.22 & 0.86 & & & & & \\
\hline 2 Perceived usefulness of IT & 4.26 & 0.81 & 0.52 & & & & \\
\hline 3 Perceived ease of use of IT & 4.31 & 1.06 & 0.47 & 0.51 & & & \\
\hline 4 Attitude toward electronic library & 4.24 & 0.89 & 0.43 & 0.49 & 0.46 & & \\
\hline 5 electronic library intention & 4.27 & 0.74 & 0.44 & 0.43 & 0.39 & 0.46 & \\
\hline 6 electronic library use & 4.31 & 0.81 & 0.42 & 0.41 & 0.38 & 0.47 & 0.43 \\
\hline
\end{tabular}

Note: $\mathrm{N}=306$. All correlations are significant at 0.01 level

Table 2 Convergent validity.

\begin{tabular}{|l|l|l|}
\hline Variables & Factor loading & $\mathrm{t}$-value \\
\hline 1 Personal innovativeness in IT & $0.45-0.64$ & $10.30-19.26$ \\
\hline 2 Perceived usefulness of IT & $0.37-0.52$ & $8.52-16.85$ \\
\hline 3 Perceived ease of use of IT & $0.41-0.65$ & $10.10-17.68$ \\
\hline 4 Attitude toward electronic library & $0.43-0.59$ & $10.54-15.26$ \\
\hline 5 electronic library intention & $0.50-0.69$ & $11.22-16.64$ \\
\hline 6 electronic library use & $0.41-0.79$ & $9.24-17.54$ \\
\hline
\end{tabular}




\section{Exploring Factors Facilitating Electronic Library Use}

\section{Hypothesis testing}

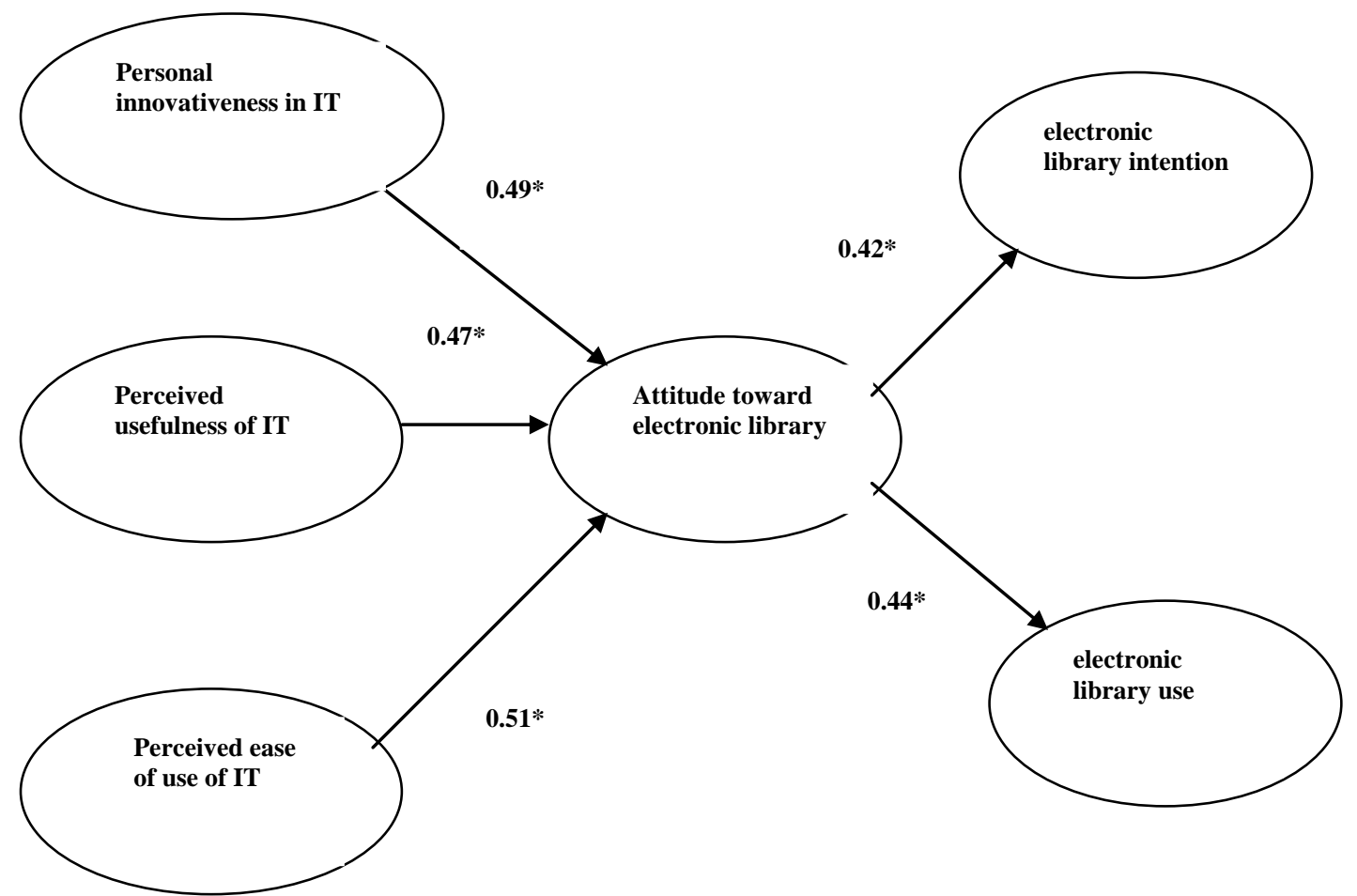

Notes: Standardized path coefficients are reported; $* \mathrm{p}<0.001$.

Figure 1. Original conceptual model.

Figure 1 revealed that the fit statistics of model were within the recommended range (chi-square value $=270.48, d . f .=143$ $(\mathrm{p}<0.001), \quad \mathrm{RMSEA}=0.071 ; \quad$ CFI $=0.91 ; \quad$ IFI $=0.91$; $\mathrm{NFI}=0.92$ ), thereby suggesting that the model fits the data. Owing to the better modified model than the original one, this study tested the hypotheses according to its parameter estimates.

In term of Hypothesis 1, as seen in Figure 1, the coefficient for personal innovativeness in IT $(\gamma=0.49, \mathrm{p}<0.001)$, perceived usefulness of IT $(\gamma=0.47, \mathrm{p}<0.001)$ and perceived ease of use of IT $(\gamma=0.51, p<0.001)$ were significant as we expected. The links to attitude toward electronic library from personal innovativeness in IT (H1a), perceived usefulness of IT (H1b), and perceived ease of use of IT (H1c) are completely supported.

As to hypothesis 2, analytical results demonstrate that attitude toward electronic library had a positive effect on electronic library intention $(\beta=0.42, p<0.001)$ and electronic library use $(\beta=0.44 \mathrm{p}<0.001)$. The above findings demonstrated that hypothesis 2 was fully supported .

\section{DISCUSSION AND CONCLUSION}

Although electronic library is commonly seen as a new trend in modern times, to the authors' knowledge, there are few studies exploring factors influencing electronic library use. To fill the gap, this study was to empirically explore factors that may affect electronic library use. Data collected from Taiwan's users. Overall, the findings fully supported the hypotheses. This study observed that personal innovativeness in IT, perceived usefulness of IT and perceived ease use of IT positively affected attitude toward electronic library.
Moreover, this study demonstrated that attitude toward electronic library exerts a positive effect on electronic library intention and electronic library use.

One limitation is the causal relationships among constructs. Although, this study developed the model that the positive effect of personal innovativeness in IT, perceived usefulness of IT and perceived ease of use of IT on attitude toward electronic library. In addition, attitude toward electronic library has a positive effect on electronic library intention and electronic library use. The relationships among constructs need to be further investigated.

\section{REFERENCES}

[1] Agarwal, R. and Prasad, J. (1998). A Conceptual and Operational Definition of Personal Innovativeness in the Domain of Information Technology", Information Systems Research, Vol. 9 No. 2, pp. 204-215.

[2] Akpojotor, L. O. (2017). Perception of Ease and Usefulness of Electronic Information Resources among Postgraduate Students of Library and Information Science in Southern Nigeria Universities. Journal of Applied Information Science and Technology, 10(1), 62-72

[3] Armstrong, G., and Kotler, P. (2000), Marketing, Paper presented at the $5^{\text {th }}$ ed., Prentice-Hall, Englewood Cliffs, 153-154.

[4] Assael, H. (1987). Consumer behavior and marketing action. Boston, Mass: Kent Publishing.

[5] Barclay, D.W., Thompson, R. and Higgins, C. (1995), "The partial least squares approach to causal modelling: personal computer adoption and use an illustration", Technology Studies, Vol. 2 No. 2, pp. 285-309.

[6] Bentler, P.M. (1990), "Comparative fit indexes in structural models", Psychological Bulletin, Vol. 107, pp. 238-46.

[7] Bentler, P.M. and Bonett, D.G. (1980), "Significant tests and goodness of fit in the analysis of covariance structures", Psychological Bulletin, Vol. 88 No. 3,pp. 588-606.

[8] Bollen, K.A. (1989), "A new incremental fit index for general structural models", Sociological Methods and Research, Vol. 17, pp. 303-16.

[9] Davis, F.D. (1989), "Perceived usefulness, perceived ease of use, and user acceptance of information technology", MIS Quarterly, Vol. 13 No. 3, pp. 319-340. 
[10] DeLone, W.H. and Mclean, E.R. (1992), Information system success: The quest for the dependent variable. Information System Research, Vol 3, pp.60-95.

[11] Edem, N.B \& Egbe, N (2018). Availability and utilization of electronic Resources by postgraduate students in a Nigerian University library. A case study of University of Calabar, Nigeria. Information and Knowledge Management, 6(2), 60-70.

[12] Fornell, C. and Larcker, D.F. (1981), "Evaluating structural equation models with unobservable variables and measurement error", Journal of Marketing Research, Vol. 19 No. 1, pp. 39-50.

[13] Forrester. (2012), "Key Strategies to Capture and Measure the Value of Consumerization of IT", A Forrester Consulting Thought Leadership Paper Commissioned by Trend Micro".

[14] Grandom, E., and Mykytyn, P. (2004), "Theory-based instrumentation to measure the intention to use electronic commerce in small and medium sized businesses", Journal of Computer Information Systems, Vol.44, pp.44-57.

[15] Haque, A., Sadeghzadeh, J., and Khatibi, A. (2006), "Identifying potentiality online sales in Malaysia: A study on customer relationships online shopping", Journal of Applied Business Research, Vol.22, pp.119-130.

[16] Hopkins, N., Sylvester, A. and Tate, M. (2013), Motivations For BYOD: An Investigation Of The Contents Of A 21st Century School Bag, ECIS 2013 Completed Research.

[17] Hu, L. and Bentler, P.M. (1999), "Cutoff criteria for fit indexes in covariance structure analysis: Conventional criteria versus new alternatives", Structural Equation Modeling, Vol. 6, pp. 1-55.

[18] Lewis, W., Agarwal, R. and Sambamurthy, V. (2003), "Sources of Influence on Beliefs about Information Technology Use: An Empirical Study of Knowledge Workers", MIS Quarterly, Vol. 27 No. 4, pp. $657-678$.

[19] Nunnally, J.C. (1978), Psychometric Theory, McGraw-Hill, New York.

[20] Nunnally, J. C., and Bernstein, I. H. (1994). Psychometric theory (3rd ed.). New York: McGraw-Hill.

[21] Quadri, G.O, Adetimirin, A.E. \& Idowu, O.A (2018). A study of availability and utilization of library electronic resources by undergraduate students in private universities in Ogun, State, Nigeria. International Journal of Library and Information Science, 6(3), 28-34.

[22] Schiffman, L. G., and Kanuk, L. L. (2000). Consumer behavior. Wisconsin: Prentice Hall.

[23] Taylor, S. and Todd, P. A. (1995), "Decomposition of cross effects in the theory of planned behavior: A study of consumer adoption intentions", International Journal of Research in Marketing, Vol.12, pp.137-155.

[24] Toyo, O. D. (2017). Undergraduates' Information Literacy Skills and the Use of Electronic Resources in Delta State University, Abraka, Nigeria. International Journal of Education and Evaluation, 3, 28-35.

[25] Udell, J. G. (1965), "Can Attitude Measurement Predict Consumer Behaviour". Journal of Marketing. Vol.29, pp.46-50.

[26] Vantomme, D., Geuens, M., De Houwer, J. and De Pelsmacker, P. (2005), "Implicit attitudes toward green consumer behaviour". Psychologica belgica, Vol.45, pp.217-239.

[27] Weeger, A. and Gewald, H. (2014), "Factors Influencing Future Employees Decision-Making to Participate in a BYOD Program: Does Risk Matter?", Proceedings of the European Conference on Information Systems (ECIS), Tel-Aviv, Israel.

[28] Willis, D. (2013), "Bring Your Own Device : The Facts and the Future", Gartner, No. April. 